\title{
2-Styrylchromones: Novel strong scavengers of reactive oxygen and nitrogen species
}

\author{
Ana Gomes, ${ }^{a}$ Eduarda Fernandes, ${ }^{\mathrm{a}, *}$ Artur M. S. Silva, ${ }^{\mathrm{b}}$ Clementina M. M. Santos, ${ }^{\mathrm{b}, \mathrm{c}}$ \\ Diana C. G. A. Pinto, ${ }^{b}$ José A. S. Cavaleiro ${ }^{b}$ and José L. F. C. Lima ${ }^{\mathrm{a}}$ \\ ${ }^{a}$ REQUIMTE, Departamento de Química-Física, Faculdade de Farmácia, Universidade do Porto, \\ Rua Aníbal Cunha, 164, 4099-030 Porto, Portugal \\ ${ }^{\mathrm{b}}$ Departamento de Química, Universidade de Aveiro, 3810-193 Aveiro, Portugal \\ ${ }^{\mathrm{c}}$ Department of Agro-Industries, Escola Superior Agrária de Bragança, Campus de Santa Apolónia, 5301-855 Bragança, Portugal
}

Received 16 February 2007; revised 14 June 2007; accepted 26 June 2007

Available online 29 June 2007

\begin{abstract}
Styrylchromones are a small group of naturally occurring chromones, vinylogues of flavones (2-phenylchromones). Natural and synthetic 2-styrylchromones have been tested in different biological systems, showing activities with potential therapeutic applications. In particular, the potential and hitherto understudied antioxidant behavior of these compounds has been raised as a matter of interest. Thus the present work consisted in the study of the in vitro scavenging activities for reactive oxygen species (ROS) and reactive nitrogen species (RNS) of various 2-styrylchromone derivatives and structurally similar flavonoids. Some of the studied 2-styrylchromones proved to be extremely efficient scavengers of the different ROS and RNS, showing, in some cases, $\mathrm{IC}_{50} \mathrm{~S}$ under $1 \mu \mathrm{M}$. The hydroxylation pattern of 2-styrylchromones, especially in the B-ring but also in the A ring, modulates the activity of these compounds, the catecholic derivatives being the most effective scavengers. The styryl pattern also contributes to their observed outstanding antioxidant activity. In conclusion, the scavenging activities for ROS/RNS of 2-styrylchromone derivatives, here shown for the first time, provide novel and most promising compounds to be applied as antioxidants.
\end{abstract}

\section{Introduction}

2-Styrylchromones are a small group of naturally occurring chromones, vinylogues of flavones (2-phenylchromones). Several analogues of these compounds have been synthesized and tested in different biological systems, showing different activities with potential therapeutic application, even before the first isolation of natural 2-styrylchromones from the green algae Chrysophaem taylori in 1986. ${ }^{1,2}$ The natural derivatives were demonstrated to possess cytotoxic activity against leukemia cells, ${ }^{1,2}$ and those obtained by synthesis exhibited antiallergic, ${ }^{3}$ antiviral, ${ }^{4}$ antitumor, ${ }^{5}$ antagonism of A3 adenosine receptor, ${ }^{6}$ xanthine oxidase inhibitor, ${ }^{7}$ hepatoprotective against pro-oxidant agents, ${ }^{8}$ and antioxidant properties. ${ }^{9}$ The antioxidant behavior of these compounds is a matter of particular interest, as previously demonstrated by their strong protective effects

Keywords: 2-Styrylchromones; Reactive oxygen species; Reactive nitrogen species; Scavenging activity; Antioxidant activity.

* Corresponding author. Tel.: +351 222078968; fax: +351 222004427; e-mail: egracas@ff.up.pt against pro-oxidant agents observed in cellular systems $\mathrm{s}^{8}$ and in non-cellular systems. ${ }^{9}$ The main contributing factor to the oxidative stress-related pathophysiologies is the overproduction of reactive oxygen species (ROS) and reactive nitrogen species (RNS). A good example of endogenous overgeneration of ROS and RNS occurs during inflammatory processes. Phagocytosis, which occurs during inflammation in a variety of cells, namely monocytes, neutrophils, eosinophils, and macrophages, is accompanied by a dramatic increase in oxygen consumption (respiratory burst) resulting firstly in the formation of superoxide radical $\left(\mathrm{O}_{2}{ }^{-}\right)$through the activity of a plasma-membrane NADPH oxidase. ${ }^{10,11}$ $\mathrm{O}_{2} \cdot{ }^{--}$produced in vivo is quickly converted to hydrogen peroxide $\left(\mathrm{H}_{2} \mathrm{O}_{2}\right)$ spontaneously or by the enzyme superoxide dismutase (SOD). ${ }^{12}$ Although being a rather unreactive molecule, $\mathrm{H}_{2} \mathrm{O}_{2}$ interacts with transition metal ions generating the hydroxyl radical (HO'). This is one of the strongest oxidizing agents, producing severe damage in its vicinity and initiating lipid peroxidation due to its well-known reactivity with polyunsaturated fatty acids, which results in the production of peroxyl radical (ROO') and other cytotoxic agents. ${ }^{12-14}$ Moreover, the 
enzyme myeloperoxidase (MPO), a hydrogen peroxide oxidoreductase that is specifically found in mammalian granulocytic leukocytes, including neutrophils, monocytes, basophils, and eosinophils, catalyzes the reaction of chloride ions and $\mathrm{H}_{2} \mathrm{O}_{2}$ with the formation of hypochlorous acid ( $\mathrm{HOCl})$, a powerful bactericidal agent. ${ }^{15}$ On the other hand, singlet oxygen $\left({ }^{1} \mathrm{O}_{2}\right)$, a highly reactive form of $\mathrm{O}_{2}$, can be produced in vivo by a range of peroxidase enzymes (e.g., myeloperoxidase, lactoperoxidase, horseradish peroxidase, and chloroperoxidase) and during lipoxygenase-catalyzed reactions. ${ }^{1} \mathrm{O}_{2}$ can also be generated in reactions involving ozone and during lipid peroxidation. ${ }^{16}$

Nitric oxide ( $\left.{ }^{\circ} \mathrm{NO}\right)$ is produced in different cell types by a family of isoenzymes termed nitric oxide synthases (NOS) and is involved in various physiological functions. Using again the inflammatory process as example, during the host defense against pathogenic microorganisms, nitric oxide is produced by the inducible NOS existent in activated macrophages and neutrophils. Identified as a cytotoxic factor, NO produced in these conditions is responsible for immunity. Additionally it is involved in the pathogenesis of some conditions including inflammation. ${ }^{17,18}$ Besides its own pro-inflammatory effects, 'NO can exert its toxicity by generating more destructive reactive species, particularly $\mathrm{ONOO}^{-}$, by reacting with $\mathrm{O}_{2}{ }^{-{ }^{-}} \cdot{ }^{19}$ Although the ROS and RNS produced by phagocytes represent an extremely important mechanism of host defense, their overproduction may provoke or exacerbate damage in inflammatory sites. ${ }^{20,21}$

Of note, 2-styrylchromones have structural similarities with flavonoids, particularly those belonging to the class of flavones. Flavonoids have been deeply studied and have shown to possess innumerous biological activities from which the antioxidant properties are the best-described. ${ }^{22-27}$ Considering the structural similarities, some of these properties are likely to be shared with 2styrylchromones, although it needs to be experimentally confirmed. Thus, the present work consisted in studying the scavenging activities for the above-referred ROS and RNS of various 2-styrylchromone derivatives (Fig. 1) in order to better understand their antioxidant potentialities. Simultaneously, five flavones and one flavonol (Fig. 1) were used as positive controls. This allowed to take advantage from the existing knowledge about flavonoids and helped to interpret the results. The ultimate aim of this investigation was to look up for structure-activity relationships concerning the scavenging studies and to select the most promising compounds as new antioxidant therapeutic agents.

\section{Results}

\subsection{Superoxide radical scavenging activity}

The $\mathrm{O}_{2}{ }^{--}$-dependent reduction of NBT was prevented by all 2-styrylchromones from group 1, with $\mathrm{IC}_{50} \mathrm{~S}$ varying from 48.9 to $80.4 \mu \mathrm{M}$. Compounds $\mathbf{1 A}$ and $\mathbf{1 B}$ were the most effective of the group. Compounds $\mathbf{2 A}$ and $\mathbf{2 B}$ were also able to scavenge $\mathrm{O}_{2}{ }^{--}$and their $\mathrm{IC}_{50} \mathrm{~s}$ matched the range of values of group 1 (Table 1). The effect shown by $\mathbf{2 D}$ is only slightly increased along the studied concentration range, reaching only a $32 \%$ effect at the highest tested concentration $(125 \mu \mathrm{M})$. Compound 3A reached a $27 \%$ effect at $31.2 \mu \mathrm{M}$, which did not increase

\section{2-Styrylchromones}
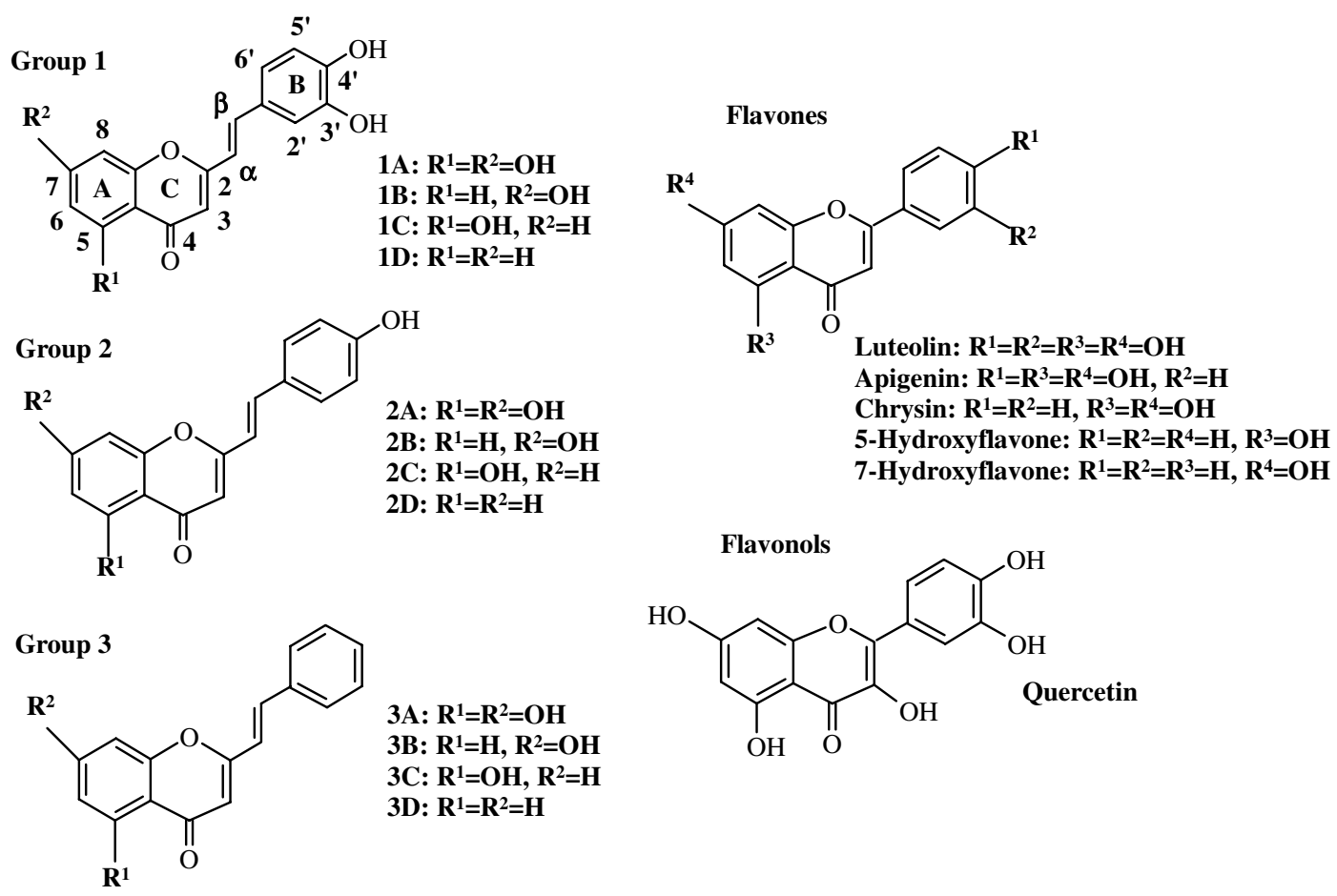

3A: $\mathbf{R}^{1}=\mathrm{R}^{2}=\mathrm{OH}$

3B: $\mathbf{R}^{1}=\mathrm{H}, \mathbf{R}^{2}=\mathrm{OH}$

3C: $\mathbf{R}^{1}=\mathrm{OH}, \mathrm{R}^{2}=\mathrm{H}$<smiles>O=c1c(O)c(-c2ccc(O)c(O)c2)oc2cc(O)cc(O)c12</smiles>

3D: $\mathbf{R}^{1}=\mathbf{R}^{2}=\mathbf{H}$

Figure 1. Chemical structures of the studied 2-styrylchromones and flavonoids. 
Table 1. $\mathrm{O}_{2} \cdot{ }^{-}, \mathrm{H}_{2} \mathrm{O}_{2}, \mathrm{HOCl}$, and ${ }^{1} \mathrm{O}_{2}$ scavenging activities $\left(\mathrm{IC}_{50}\right.$, mean $\left.\pm \mathrm{SE}\right)$ of the studied 2-styrylchromones, flavonoids, and positive controls

\begin{tabular}{|c|c|c|c|c|}
\hline \multirow[t]{2}{*}{ Compound } & \multicolumn{4}{|c|}{$\mathrm{IC}_{50}(\mu \mathrm{M})$} \\
\hline & $\mathrm{O}_{2}^{\cdot-}$ & $\mathrm{H}_{2} \mathrm{O}_{2}$ & $\mathrm{HOCl}$ & ${ }^{1} \mathrm{O}_{2}$ \\
\hline \multicolumn{5}{|l|}{ 2-Styrylchromones } \\
\hline 1A & $48.9 \pm 1.2$ & $50.3 \pm 7.8$ & $3.9 \pm 0.2$ & $6.5 \pm 0.9$ \\
\hline 1B & $51.0 \pm 1.4$ & $114.2 \pm 19.1$ & $18.0 \pm 1.8$ & $10.1 \pm 1.3$ \\
\hline $1 \mathrm{C}$ & $80.4 \pm 7.1$ & $48.9 \pm 5.5$ & $16.9 \pm 1.1$ & $4.9 \pm 0.6$ \\
\hline 1D & $71.3 \pm 4.2$ & $182.8 \pm 3.2$ & $32.1 \pm 1.5$ & $7.9 \pm 0.9$ \\
\hline $2 \mathrm{~A}$ & $77.7 \pm 5.5$ & $36 \% *^{250 \mu \mathrm{M}}$ & $8.5 \pm 0.3$ & $182.8 \pm 2.9$ \\
\hline $2 B$ & $66.2 \pm 6.2$ & $\mathrm{NA}^{250 \mu \mathrm{M}}$ & $92.0 \pm 7.1$ & $265.8 \pm 27.5$ \\
\hline $2 \mathrm{C}$ & $\mathrm{NA}^{100 \mu \mathrm{M}}$ & $40 \% *^{250 \mu \mathrm{M}}$ & $29 \% * 25 \mu \mathrm{M}$ & $29 \% * *^{40 \mu \mathrm{M}}$ \\
\hline 2D & $32 \% * 125 \mu \mathrm{M}$ & $\mathrm{NA}^{250 \mu \mathrm{M}}$ & $34 \% *^{100 \mu \mathrm{M}}$ & $245.0 \pm 6.3$ \\
\hline $\mathbf{3 A}$ & $27 \% *^{125 \mu \mathrm{M}}$ & $\mathrm{NA}^{250 \mu \mathrm{M}}$ & $5.7 \pm 0.7$ & $162.6 \pm 10.0$ \\
\hline 3B & $40 \% *^{125 \mu \mathrm{M}}$ & $\mathrm{NA}^{250 \mu \mathrm{M}}$ & $72.3 \pm 5.0$ & $\mathrm{NA}^{1 \mathrm{mM}}$ \\
\hline $3 \mathrm{C}$ & $\mathrm{NA}^{125 \mu \mathrm{M}}$ & $\mathrm{NA}^{250 \mu \mathrm{M}}$ & $17 \% *^{50 \mu \mathrm{M}}$ & $\mathrm{NA}^{100 \mu \mathrm{M}}$ \\
\hline 3D & $\mathrm{NA}^{125 \mu \mathrm{M}}$ & $\mathrm{NA}^{250 \mu \mathrm{M}}$ & $10 \% *^{125 \mu \mathrm{M}}$ & $\mathrm{NA}^{200 \mu \mathrm{M}}$ \\
\hline \multicolumn{5}{|l|}{ Flavonoids } \\
\hline Quercetin & $47.3 \pm 4.4$ & $785.0 \pm 45.0$ & $1.1 \pm 0.1$ & $5.3 \pm 0.3$ \\
\hline Luteolin & $58.5 \pm 4.6$ & $900.2 \pm 42.1$ & $7.1 \pm 1.5$ & $23.4 \pm 2.4$ \\
\hline Apigenin & $35 \% * 100 \mu \mathrm{M}$ & $\mathrm{NA}^{250 \mu \mathrm{M}}$ & $3.9 \pm 0.4$ & $30 \% *^{1} \mathrm{mM}$ \\
\hline Chrysin & $\mathrm{NA}^{125 \mu \mathrm{M}}$ & $\mathrm{NA}^{250 \mu \mathrm{M}}$ & $3.9 \pm 0.2$ & $\mathrm{NA}^{500 \mu \mathrm{M}}$ \\
\hline 5-Hydroxyflavone & $\mathrm{NA}^{125 \mu \mathrm{M}}$ & $\mathrm{NA}^{250 \mu \mathrm{M}}$ & $17 \% *^{50 \mu \mathrm{M}}$ & $\mathrm{NA}^{100 \mu \mathrm{M}}$ \\
\hline 7-Hydroxyflavone & $\mathrm{NA}^{125 \mu \mathrm{M}}$ & $\mathrm{NA}^{250 \mu \mathrm{M}}$ & $146.5 \pm 12.7$ & $\mathrm{NA}^{1 \mathrm{mM}}$ \\
\hline \multicolumn{5}{|l|}{ Positive controls } \\
\hline Propyl gallate & $24.6 \pm 3.2$ & - & - & - \\
\hline Ascorbic acid & - & $625.5 \pm 49.6$ & - & - \\
\hline Lipoic acid & - & - & $2.4 \pm 0.1$ & - \\
\hline Penicillamine & - & - & - & $4.9 \pm 0.2$ \\
\hline
\end{tabular}

${ }_{\mathrm{NA}} \mathrm{No}$ activity was found up to the highest tested concentration (in superscript); * scavenging effect (mean \%) at the highest tested concentration (in superscript).

with higher concentrations (up to $125 \mu \mathrm{M}$ ). Compound 3B provided a $40 \%$ effect at the maximum tested concentration $(125 \mu \mathrm{M})$. The other 2-styrylchromone derivatives were unable to scavenge $\mathrm{O}_{2} \cdot{ }^{--}$within the studied concentration ranges.

Quercetin and luteolin could scavenge $\mathrm{O}_{2}{ }^{--}$with an efficiency comparable to compounds $\mathbf{1 A}$ and $\mathbf{1 B}$ (Table 1). Apigenin reached a 35\% steady-state effect along the studied concentration range $(12.5-100 \mu \mathrm{M})$. No scavenging effect was observed for chrysin, 7-hydroxyflavone, and 5-hydroxyflavone. The $\mathrm{IC}_{50}$ of the positive control propyl gallate was $24.6 \pm 3.2 \mu \mathrm{M}$.

\subsection{Hydrogen peroxide scavenging activity}

Only 2-styrylchromones from group 1 could scavenge $\mathrm{H}_{2} \mathrm{O}_{2}$ in a concentration-dependent manner. Compounds $1 \mathrm{~A}$ and $\mathbf{1 C}$ presented a very similar activity, with $\mathrm{IC}_{50}$ s rounding the $50 \mu \mathrm{M}$. Compounds $\mathbf{1 B}$ and $\mathbf{1 D}$ were less efficient and provided $\mathrm{IC}_{50} \mathrm{~s}$ of $114.2 \pm 19.1 \mu \mathrm{M}$ and $182.8 \pm 3.2 \mu \mathrm{M}$, respectively (Table 1 ). Compounds $\mathbf{2 A}$ and $2 \mathrm{C}$ could only reach a $36 \%$ and a $30 \%$ effect, respectively, at the highest tested concentration $(250 \mu \mathrm{M})$. Compounds 2B and 2D, and the compounds from group 3 were completely ineffective up to the highest tested concentration $(250 \mu \mathrm{M})$.

Among the tested flavonoids, only quercetin and luteolin were able to scavenge $\mathrm{H}_{2} \mathrm{O}_{2}$. However, these compounds were much less active than the 2styrylchromones from group 1 . The $\mathrm{IC}_{50}$ obtained for quercetin was $785.0 \pm 45.0 \mu \mathrm{M}$, while for luteolin it was $900.2 \pm 42.1 \mu \mathrm{M}$. The antioxidant ascorbic acid provided an $\mathrm{IC}_{50}$ of $625.5 \pm 49.6 \mu \mathrm{M}$.

\subsection{Hypochlorous acid scavenging activity}

2-Styrylchromones from group 1 were able to efficiently scavenge $\mathrm{HOCl}$, in a concentration-dependent manner (Table 1). Compound $\mathbf{1 A}$ was considerably more efficient than the rest of the group, presenting an $\mathrm{IC}_{50}$ of $3.9 \pm 0.2 \mu \mathrm{M}$, followed by $\mathbf{1 B}$ and $\mathbf{1 C}$, with comparable effects $\left(\mathrm{IC}_{50} \mathrm{~s}\right.$ of $18.0 \pm 0.2 \mu \mathrm{M}$ and $16.9 \pm 1.1 \mu \mathrm{M}$, respectively), and by $1 \mathrm{D}\left(\mathrm{IC}_{50}=32.1 \pm 1.5 \mu \mathrm{M}\right)$, which was the least potent of the group. From the group 2, only $\mathbf{2 A}$ and 2B have shown a concentration-dependent activity, although the first $\left(\mathrm{IC}_{50}=8.5 \pm 0.3 \mu \mathrm{M}\right)$ was noticeably more potent than the second $\left(\mathrm{IC}_{50}=92.0 \pm 7.1 \mu \mathrm{M}\right)$. Compound 2C reached no more than a $29 \%$ effect, although it could only be tested up to $25 \mu \mathrm{M}$ due to its low solubility. Compound 2D reached a $34 \%$ effect at the highest tested concentration $(100 \mu \mathrm{M})$. From group 3 , only $\mathbf{3 A}$ and $\mathbf{3 B}$ showed an effect dependent on the concentration, with $3 \mathrm{~A}\left(\mathrm{IC}_{50}=5.7 \pm 0.7 \mu \mathrm{M}\right)$ being much more effective than 3B $\left(\mathrm{IC}_{50}=72.3 \pm 5.0 \mu \mathrm{M}\right)$ (Table 1). Compounds 3C and 3D presented only a slight effect of $17 \%$ and $10 \%$ at the maximum tested concentrations (50 and $125 \mu \mathrm{M}$, respectively). It should be noticed that 2A and 3A presented comparable effects, and their potencies were closer to $\mathbf{1 A}$ than the other compounds from group 1 (Table 1). Quercetin was the most effective of the tested flavonoids $\left(\mathrm{IC}_{50}=1.1 \pm 0.1 \mu \mathrm{M}\right)$, followed by apigenin and chrysin, with equal $\mathrm{IC}_{50} \mathrm{~S}(3.9 \mu \mathrm{M} \pm 0.4$ 
and $3.9 \mu \mathrm{M} \pm 0.2)$, and luteolin $\left(\mathrm{IC}_{50}=7.1 \pm 1.5 \mu \mathrm{M}\right)$. 7Hydroxyflavone was also able to scavenge $\mathrm{HOCl}$, although it has revealed to be much less potent than the above-referred flavonoids $\left(\mathrm{IC}_{50}=146.5 \pm 12.7 \mu \mathrm{M}\right)$. 5 -Hydroxyflavone revealed only a vestigial effect at the maximum tested concentration $(17 \%$ at $50 \mu \mathrm{M})$. Lipoic acid efficiently scavenged $\mathrm{HOCl}\left(\mathrm{IC}_{50}\right.$ of $\left.2.4 \pm 0.1 \mu \mathrm{M}\right)$.

\subsection{Singlet oxygen scavenging activity}

2-Styrylchromones from group 1 were shown to be potent scavengers of ${ }^{1} \mathrm{O}_{2}$ in a concentration-dependent manner and were effective in the low micromolar range (Table 1). In what concerns group 2, $\mathbf{2 A}$ was the most potent if we consider the $\mathrm{IC}_{50}$ values (Table 1). However, the obtained $\mathrm{IC}_{20}$ for $2 \mathrm{C}(28.9 \pm 4.3 \mu \mathrm{M})$ was slightly lower than that of $2 \mathrm{~A}(35.1 \pm 2.9 \mu \mathrm{M})$. Yet, it was not possible to test $\mathbf{2 C}$ beyond the concentration of $40 \mu \mathrm{M}$ due to the precipitation that occurred in the sample wells at higher concentrations. Compounds 2B and 2D presented a very similar effect, but were less potent than 2A (Table 1). Compound $\mathbf{3 A}$ was able to scavenge ${ }^{1} \mathrm{O}_{2}$ in a concentration-dependent manner, presenting an $\mathrm{IC}_{50}$ of $162.6 \pm 10.0 \mu \mathrm{M}$. Compounds 3B, 3C, and 3D did not show any scavenging activity up to the maximum tested concentrations $(1000,100$, and $200 \mu \mathrm{M}$, respectively). In what concerns the tested flavonoids, quercetin showed an activity similar to the 2-styrylchromones from group 1, with an $\mathrm{IC}_{50}$ of $5.3 \pm 0.3 \mu \mathrm{M}$, very close to the values obtained for $\mathbf{1 A}$ and 1C (Table 1). Luteolin revealed to be less potent than quercetin or any of the compounds from the referred group $\left(\mathrm{IC}_{50}=23.4 \pm 2.4 \mu \mathrm{M}\right)$. Apigenin was able to scavenge ${ }^{1} \mathrm{O}_{2}$ although its effect had suffered only a slight increase along the studied concentration range $(100-1000 \mu \mathrm{M})$, hence it could only reach a $30 \%$ effect at the maximum tested concentration $(1 \mathrm{mM})$. The flavones chrysin, 5-hydroxyflavone, and 7-hydroxyflavone were not able to scavenge ${ }^{1} \mathrm{O}_{2}$ up to the maximum tested concentrations (500, 100, and $1000 \mu \mathrm{M}$, respectively). Penicillamine provided an $\mathrm{IC}_{50}$ of $4.9 \pm 0.2 \mu \mathrm{M}$.

The studies related to possible interferences from each one of the tested compounds with the methodology revealed that compounds $\mathbf{1 C}$ and $\mathbf{2 A}$ react with rhodamine 123 in a concentration-dependent manner, in the range of concentrations used in this assay, which can contribute to a decrease of the fluorescence signal beyond that resulting from the scavenging effect. Thus, in what concerns to these two compounds, it is possible that the results do not correctly express their ${ }^{1} \mathrm{O}_{2}$ scavenging activity.

\subsection{Peroxyl radical scavenging activity}

The results from the Oxygen Radical Absorbance Capacity (ORAC) assay are listed in Table 2 . All the compounds from group 1 were able to delay the ROO-dependent oxidation of fluorescein. From group 2, only $\mathbf{2 C}$ was not effective. Compound $\mathbf{3 A}$ was the only active compound from group 3. In what concerns flavonoids, apigenin provided the highest ORAC value, followed by luteolin, quercetin, and chrysin. 5-Hydroxyflavone and 7-hydroxyflavone showed no effect in this assay.
Table 2. ROO' scavenging activity of the tested 2-styrylchromones and flavonoids expressed as ORAC values (mean $\pm \mathrm{SE}$ )

\begin{tabular}{lcl}
\hline Compound & $\begin{array}{l}\mathrm{ORAC}_{\mathrm{ROO}} \pm \mathrm{SE} \\
(\mu \mathrm{M} \text { trolox equiv/ } \mu \mathrm{M} \\
\text { compound })\end{array}$ & $\begin{array}{l}\text { Concentration } \\
\text { range }(\mu \mathrm{M})\end{array}$ \\
\hline 1A & $9.15 \pm 0.20$ & $0.1-0.6$ \\
1B & $7.17 \pm 0.15$ & $0.1-0.6$ \\
1C & $6.23 \pm 0.09$ & $0.2-0.8$ \\
1D & $5.57 \pm 0.37$ & $0.2-0.8$ \\
2A & $8.99 \pm 0.42$ & $0.1-0.6$ \\
2B & $6.17 \pm 0.34$ & $0.1-0.6$ \\
2C & $\mathrm{NA}$ & $0.1-2.0$ \\
2D & $5.84 \pm 0.38$ & $0.1-0.6$ \\
3A & $3.77 \pm 0.24$ & $0.1-0.6$ \\
3B & $\mathrm{NA}$ & $0.1-2.0$ \\
3C & $\mathrm{NA}$ & $0.1-2.0$ \\
3D & $\mathrm{NA}$ & $0.1-2.0$ \\
Luteolin & $7.76 \pm 0.38$ & $0.1-0.8$ \\
Quercetin & $5.98 \pm 0.42$ & $0.2-0.6$ \\
Apigenin & $10.89 \pm 0.60$ & $0.05-0.5$ \\
Chrysin & $4.66 \pm 0.35$ & $0.1-0.8$ \\
5-Hydroxyflavone & $\mathrm{NA}$ & $0.1-2.0$ \\
7-Hydroxyflavone & $\mathrm{NA}$ & $0.1-2.0$ \\
\hline
\end{tabular}

${ }^{\mathrm{NA}} \mathrm{No}$ activity was found within the assayed concentration range.

\subsection{Peroxynitrite scavenging activity}

The $\mathrm{ONOO}^{-}$-induced oxidation of dihydrorhodamine 123 (DHR) was very efficiently prevented by the 2 -styrylchromones from group $1 \quad\left(0.26 \pm 0.02 \mu \mathrm{M} \leqslant \mathrm{IC}_{50}\right.$ $\leqslant 0.30 \pm 0.03 \mu \mathrm{M})$ and group $2\left(1.04 \pm 0.04 \mu \mathrm{M} \leqslant \mathrm{IC}_{50}\right.$ $\leqslant 1.40 \pm 0.13 \mu \mathrm{M}$ ). From group 3, only $\mathbf{3 A}$ was effective in a concentration-dependent manner $\left(\mathrm{IC}_{50}=46.6 \pm\right.$ $7.0 \mu \mathrm{M})$. Compound 3D reached a $27 \%$ effect at the highest tested concentration $(150 \mu \mathrm{M})$. In the presence of $25 \mathrm{mM} \mathrm{NaHCO}_{3}$, the same 2-styrylchromones that were active in its absence also managed to prevent DHR's oxidation. However, while the compounds from group 1 were visibly less efficient in the presence of $\mathrm{NaHCO}_{3}$, the other 2-styrylchromones showed very similar effects in both circumstances. The relative order of potencies was the same either with or without $\mathrm{NaHCO}_{3}$ (Table 3).

Quercetin and luteolin proved to be the most active flavonoids, with $\mathrm{IC}_{50} \mathrm{~s}$ very similar to those presented by 2 -styrylchromones from group 1 . This finding was confirmed in the presence of $\mathrm{NaHCO}_{3}$ (Table 3). Apigenin and chrysin also prevented the $\mathrm{ONOO}^{-}$-induced oxidation of DHR either in the presence or in the absence of $\mathrm{NaHCO}_{3}$. Yet, the $\mathrm{IC}_{50} \mathrm{~S}$ of both compounds were lower in the presence of $\mathrm{NaHCO}_{3}$, with a more noticeable difference for apigenin (Table 3). 5-Hydroxyflavone and 7-hydroxyflavone were ineffective in both assays. Ebselen, a selenium compound with well-known $\mathrm{ONOO}^{-}$scavenging activity, provided an $\mathrm{IC}_{50}$ of $0.91 \pm 0.06 \mu \mathrm{M}$ in the absence of $\mathrm{NaHCO}_{3}$ and $4.63 \pm 0.44 \mu \mathrm{M}$ in its presence.

\subsection{Nitric oxide scavenging activity}

2-Styrylchromones from group 1 were able to inhibit the NO-induced oxidation of 4,5-diaminofluorescein (DAF-2), in a concentration-dependent manner. The $\mathrm{IC}_{50} \mathrm{~s}$ obtained for this group were very low, varying 
Table 3. $\mathrm{NO}$ and $\mathrm{ONOO}^{-}$(with and without $25 \mathrm{mM} \mathrm{NaHCO}_{3}$ ) scavenging activities $\left(\mathrm{IC}_{50}\right.$, mean $\left.\pm \mathrm{SE}\right)$ of the studied 2-styrylchromones, flavonoids, and positive controls

\begin{tabular}{|c|c|c|c|}
\hline \multirow[t]{2}{*}{ Compound } & \multicolumn{3}{|c|}{$\mathrm{IC}_{50}(\mu \mathrm{M})$} \\
\hline & $\cdot \mathrm{NO}$ & $\begin{array}{l}\mathrm{ONOO}^{-} \\
\text {without } \\
\mathrm{NaHCO}_{3}\end{array}$ & $\begin{array}{l}\mathrm{ONOO}^{-} \\
\text {with } \mathrm{NaHCO}_{3}\end{array}$ \\
\hline \multicolumn{4}{|l|}{ 2-Styrylchromones } \\
\hline $1 \mathrm{~A}$ & $0.51 \pm 0.13$ & $0.26 \pm 0.02$ & $0.63 \pm 0.03$ \\
\hline 1B & $0.29 \pm 0.01$ & $0.30 \pm 0.03$ & $0.61 \pm 0.08$ \\
\hline $1 \mathrm{C}$ & $0.24 \pm 0.04$ & $0.26 \pm 0.04$ & $0.51 \pm 0.05$ \\
\hline 1D & $0.34 \pm 0.09$ & $0.24 \pm 0.02$ & $0.44 \pm 0.02$ \\
\hline $2 A$ & $21 \% *^{250 \mu \mathrm{M}}$ & $1.25 \pm 0.14$ & $1.21 \pm 0.16$ \\
\hline 2B & $23 \% *^{250 \mu \mathrm{M}}$ & $1.40 \pm 0.13$ & $1.65 \pm 0.16$ \\
\hline $2 \mathrm{C}$ & $\mathrm{NA}^{50 \mu \mathrm{M}}$ & $1.04 \pm 0.04$ & $0.98 \pm 0.13$ \\
\hline 2D & $46 \% * 250 \mu \mathrm{M}$ & $1.20 \pm 0.17$ & $1.23 \pm 0.19$ \\
\hline 3A & $73.9 \pm 12.2$ & $46.6 \pm 7.0$ & $40.6 \pm 2.2$ \\
\hline 3B & $\mathrm{NA}^{250 \mu \mathrm{M}}$ & $\mathrm{NA}^{500 \mu \mathrm{M}}$ & $\mathrm{NA}^{500 \mu \mathrm{M}}$ \\
\hline $3 \mathrm{C}$ & $\mathrm{NA}^{50 \mu \mathrm{M}}$ & $\mathrm{NA}^{62 \mu \mathrm{M}}$ & $\mathrm{NA}^{62 \mu \mathrm{M}}$ \\
\hline 3D & $\mathrm{NA}^{100 \mu \mathrm{M}}$ & $27 \% * 150 \mu \mathrm{M}$ & $27 \% * 150 \mu \mathrm{M}$ \\
\hline \multicolumn{4}{|l|}{ Flavonoids } \\
\hline Quercetin & $1.95 \pm 0.06$ & $0.26 \pm 0.03$ & $0.44 \pm 0.02$ \\
\hline Luteolin & $2.61 \pm 0.54$ & $0.30 \pm 0.05$ & $0.64 \pm 0.08$ \\
\hline Apigenin & $\mathrm{NA}^{250 \mu \mathrm{M}}$ & $76.1 \pm 8.9$ & $21.2 \pm 4.7$ \\
\hline Chrysin & $20 \% *^{250 \mu \mathrm{M}}$ & $188.1 \pm 8.2$ & $140.0 \pm 25.0$ \\
\hline 5-Hydroxyflavone & $\mathrm{NA}^{100 \mu \mathrm{M}}$ & $\mathrm{NA}^{62 \mu \mathrm{M}}$ & $\mathrm{NA}^{62 \mu \mathrm{M}}$ \\
\hline 7-Hydroxyflavone & $\mathrm{NA}^{250 \mu \mathrm{M}}$ & $\mathrm{NA}^{500 \mu \mathrm{M}}$ & $\mathrm{NA}^{500 \mu \mathrm{M}}$ \\
\hline \multicolumn{4}{|l|}{ Positive controls } \\
\hline Rutin & $3.66 \pm 0.43$ & - & - \\
\hline Ebselen & - & $0.91 \pm 0.06$ & $4.63 \pm 0.44$ \\
\hline
\end{tabular}

${ }^{\mathrm{NA}}$ No activity was found up to the highest tested concentration (in superscript); "scavenging effect (mean \%) at the highest tested concentration (in superscript).

from $0.24 \pm 0.04 \mu \mathrm{M}$ to $0.51 \pm 0.13 \mu \mathrm{M}$ (Table 3 ). The compounds $\mathbf{2 A}, \mathbf{2 B}$, and $\mathbf{2 D}$ were only able to scavenge -NO at their maximum tested concentrations $(250 \mu \mathrm{M})$ reaching the following effects: 21,23 , and $46 \%$, respectively. Compound 2C was completely ineffective, although it could only be tested up to $50 \mu \mathrm{M}$. Compound 3A presented a concentration-dependent effect with an $\mathrm{IC}_{50}$ of $73.9 \pm 12.2 \mu \mathrm{M}$. Compounds 3B, 3C, and 3D could not show any effect up to the maximum tested concentrations (250, 50, and $100 \mu \mathrm{M}$, respectively). In what concerns flavonoids, quercetin and luteolin were the only compounds able to scavenge $\mathrm{NO}$ in a concentrationdependent manner $\left(\mathrm{IC}_{50} \mathrm{~s}\right.$ of $1.95 \pm 0.06 \mu \mathrm{M}$ and $2.61 \pm$ $0.54 \mu \mathrm{M}$, respectively). Chrysin provided a $20 \%$ effect at $250 \mu \mathrm{M}$, while the other flavonoids (apigenin, 5-hydroxyflavone, and 7-hydroxyflavone) showed no scavenging activity at all. The flavonoid rutin, which is a known 'NO scavenger, provided an $\mathrm{IC}_{50}$ of $3.66 \pm 0.43 \mu \mathrm{M}$.

\section{Discussion}

The present study corroborates and extends previous findings indicating some styrylchromones as promising antioxidant pharmacophores. The scavenging activities for ROS/RNS of 2-styrylchromone derivatives are here shown for the first time, providing outstanding results, considering the nanomolar to micromolar range of the $\mathrm{IC}_{50}$ values found.
One of the main sources of $\mathrm{O}_{2} \cdot{ }^{-}$is the enzyme xanthine oxidase (XO). A previous work from our group ${ }^{7}$ has shown that the tested 2-styrylchromones have the ability to inhibit XO. In addition, several papers refer to the XO inhibitory capacity of different flavonoids, including quercetin, apigenin, chrysin, and 7-hydroxyflavone. ${ }^{28-30}$ Thus, in the present work the $\mathrm{O}_{2}{ }^{--}$scavenging activity was measured by a non-enzymatic methodology in order to avoid the confounding effects derived from the XO inhibition. 2-Styrylchromones from group 1 were all effective scavengers of $\mathrm{O}_{2}{ }^{--}$, indicating that the $3^{\prime}, 4^{\prime}$ dihydroxyl substitution on the B-ring plays an important role in what concerns $\mathrm{O}_{2}{ }^{--}$scavenging activity of 2 -styrylchromones. This comes in agreement with previous studies about the structure-activity relationships of flavonoids. ${ }^{31,32}$ In addition, the number and position of the hydroxyl groups in the A-ring also seems to contribute to the effect of these compounds. Indeed, compounds $\mathbf{1 A}$ and $\mathbf{1 B}$, with a 5,7-dihydroxyl and a 7hydroxyl substitution in the A-ring, respectively, were noticeably more potent than $1 \mathrm{C}$ and $\mathbf{1 D}$ with a 5-hydroxyl in A-ring and no hydroxyl group at all, respectively. Moreover, compounds $\mathbf{2 A}$ and $\mathbf{2 B}$, which have a phenolic instead of a catecholic B-ring, were still more active than 1C and 1D. Compounds from group 3 have shown almost no effect, indicating that an hydroxyl substituent in the B-ring is essential for the $\mathrm{O}_{2}{ }^{--}$scavenging activity. From the studied flavonoids, quercetin was slightly more effective than luteolin. This confirms the previously referred importance of the hydroxyl group on $\mathrm{C} 3$, which distinguishes quercetin (a flavonol) from luteolin (a flavone), in their radical scavenging activity potencies. This structural feature provides the conjugation between B-ring and C-ring, and contributes to the stabilization of the phenoxy radical. ${ }^{31,32}$ Of note, compound $\mathbf{1 A}$, which differs from quercetin by the presence of a styryl moiety and the absence of the hydroxyl group on $\mathrm{C} 3$, has shown an $\mathrm{O}_{2}{ }^{--}$scavenging activity very similar to the referred flavonol. This fact points to a likely contribution of the styryl moiety to the molecular stabilization, increasing the compound's antiradical activity.

The results from the $\mathrm{H}_{2} \mathrm{O}_{2}$-scavenging assay once again show the importance of the $3^{\prime}, 4^{\prime}$-catechol in the B-ring for the antioxidant activity of 2-styrylchromones. In this case, the styrylphenol derivatives were almost ineffective, and none of the compounds from group 3, with no hydroxyl substituents in the B-ring, showed any activity. In contrast to what was observed for $\mathrm{O}_{2} \cdot-$, the 5-hydroxyl substituent seems to contribute to the $\mathrm{H}_{2} \mathrm{O}_{2}$ scavenging activity more effectively than the 7-hydroxyl substituent. In fact the presence of a 7-hydroxyl group in the benzopyrone moiety does not seem to bring any great advantage to the scavenging effect. The 2-styrylchromones from group 1 were much more effective than quercetin or luteolin, which is a very interesting aspect since it shows the major role of the styryl feature on the $\mathrm{H}_{2} \mathrm{O}_{2}$ scavenging activity. This group of compounds was also much more effective than ascorbic acid, which is a well-known important dietary antioxidant.

The HOCl scavenging activity of the tested 2-styrylchromones seems to be largely affected by the number and 
position of the hydroxyl substituents on the A-ring. Although the catechol group on B-ring is indicative of a strong scavenging effect, as it happens with the above-mentioned ROS, this feature seems to be less important when a 5,7-dihydroxyl group is present in the A ring. This is clear by the analysis of the results, which shows that the most potent 2-styrylchromones are $1 \mathbf{A}, \mathbf{2 A}$, and 3A. A mono- or a non-substituted A-ring greatly decreases the $\mathrm{HOCl}$ scavenging activity of the molecule. The same conclusion can be drawn from the results of the studied flavonoids. Quercetin, luteolin, apigenin, and chrysin all provided a strong $\mathrm{HOCl}$ scavenging effect even though apigenin and chrysin lack the catechol group on the B-ring. Yet, they all have in common the 5,7-dihydroxylated A-ring, which explains the high activity. The $\mathrm{C} 3-\mathrm{OH}$ substitution seems to be another important feature the $\mathrm{HOCl}$ scavenging activity, considering the very strong effect showed by quercetin. It has been previously referred that quercetin and its derivative rutin react with $\mathrm{HOCl}$ to form stable monoand dichlorinated products, modified at the $\mathrm{C} 6$ and $\mathrm{C} 8$ sites of the A-ring, which results in even more efficient scavengers of ROS and RNS than the parent compounds. ${ }^{33}$ Considering the structural similarity between quercetin and 2-styrylchromones, particularly the compound $\mathbf{1 A}$, it is tempting to admit that these compounds may also suffer chlorination upon reaction with $\mathrm{HOCl}$ and equally generate more active antioxidant products. This is an interesting point, although it needs to be confirmed with further studies.

The ${ }^{1} \mathrm{O}_{2}$ scavenging activity of 2-styrylchromones and flavonoids seems to depend particularly on the $\mathrm{OH}$-substitution pattern in B-ring. Compounds with a $3^{\prime}, 4^{\prime}$ dihydroxyl pattern presented a considerably higher effect than those lacking this feature as it can be confirmed by the comparison of the results from group 1 with those from groups 2 and 3 . Nevertheless, the number and position of the $\mathrm{OH}$ substituents in the A-ring also contributes to the ${ }^{1} \mathrm{O}_{2}$ scavenging activity of 2-styrylchromones. An $\mathrm{OH}$ group in $\mathrm{C} 5$ seems to positively affect the scavenging behavior of the antioxidant molecule, while this substitution in $\mathrm{C} 7$ appears to bring no advantage. The studied 2-styrylchromones were shown to be more efficient scavengers of ${ }^{1} \mathrm{O}_{2}$ than the flavones with comparable structures, which means that the styryl feature increases the scavenging activity for this reactive species. Quercetin was the most effective of the tested flavonoids, showing a much lower $\mathrm{IC}_{50}$ than luteolin, its corresponding flavone. These results are in agreement with the previously shown high chemical reactivity of flavonols with ${ }^{1} \mathrm{O}_{2}$, explained by the presence of the C3-OH substituent in the C-ring. ${ }^{34}$ Nevertheless, the most effective 2-styrylchromones (1A and 1C), although lacking this substituent, were quite as active as quercetin.

In the ORAC assay quercetin proved to be a good ROO' scavenger, providing an ORAC value very close to those reported in previous similar studies. ${ }^{35,36}$ Luteolin also behaved as an excellent ROO scavenger and apigenin, contrary to the expected, provided the highest ORAC value. Rice-Evans ${ }^{25}$ considered flavonoids as ideal scavengers of peroxyl radicals and effective inhibitors of lipid peroxidation due to their favorable reduction potentials relatively to alkyl peroxyl radicals. Furthermore these compounds have the ability to interact with biomembranes, ${ }^{37}$ occupying a favorable position to interrupt radical chain reactions. The results from the present study show that some 2-styrylchromones are as good ROO scavengers as the structurally similar flavonoids, or even better in some cases. Although the $\mathrm{OH}$ substitution pattern in the B-ring seems to exert a major influence on the activity of these compounds, a clear-cut structure-activity relationship is yet to be established.

The high ROO* scavenging activity shown by some of the studied compounds may be of extreme value since, during its sustained overproduction, the walls of affected tissue cells involved become amenable to lipid peroxidation, explaining the increase of lipid peroxidation marker compounds in oxidative stress related diseases. For instance, a larger concentration of lipid peroxidation markers is detected in LDL samples of patients suffering from atherosclerosis rheumatic arthritis, after shock, or bacterial infection. ${ }^{38}$ Noticeably, some of the tested 2styrylchromones have previously shown to prevent tert-butylhydroperoxide ( $t$-BHP) induced lipid peroxidation in rat hepatocytes. ${ }^{8}$ Additionally, the compounds studied by Fernandes and coworkers reduced the prooxidant hepatotoxicity by preventing the depletion of reduced glutathione (GSH) and cell death. The results obtained in that same study showed that the B-ring catecholic derivatives were more effective hepatoprotectors than the phenolic derivatives. ${ }^{8}$

2-Styrylchromones from group 1 were the most effective derivatives to protect DHR against $\mathrm{ONOO}^{-}$-induced oxidation. The different compounds from this group showed very similar activities, which indicates that the catecholic B-ring, a common feature in the group, is the main factor responsible for the scavenging activity. Moreover, the group 2 derivatives were visibly less active than the group 1 derivatives, although their $\mathrm{IC}_{50} \mathrm{~s}$ were still very low. Thus, the $4^{\prime}$-hydroxyl group in B-ring also seems to be of extreme importance for $\mathrm{ONOO}^{-}$scavenging activity of 2-styrylchromones. The absence of an $\mathrm{OH}$ substituent in the B-ring drastically decreases the scavenging effect, as it is evident by the analysis of the results from group 3. Nevertheless, 3A was able to prevent $\mathrm{ONOO}^{-}$-induced DHR oxidation, although to a smaller extent compared to the other active compounds, which indicates that the number of $\mathrm{OH}$ groups in the A-ring is an important factor to the scavenging effect when the B-ring lacks $\mathrm{OH}$ substituents. The results obtained from quercetin and luteolin are analogous to those of 2-styrylchromones from group 1. Apigenin was a much weaker protector of DHR oxidation than the above-referred flavonoids, confirming the requirement of the $3^{\prime}, 4^{\prime}$-hydroxylation pattern to achieve a strong effect. It should be noticed, however, that the 2-styrylchromones from group 2 were considerably more effective than apigenin, which means that the styryl link increases the $\mathrm{ONOO}^{-}$scavenging activity of the phenolic B-ring derivatives. A possible explanation for this fact might be on the contribution of the styryl moiety to the stabilization of the phenoxy radical that 
is formed during the scavenging reaction, as it was previously suggested. ${ }^{8}$ The comparison between the effects of chrysin and $\mathbf{3 A}$ confirms the importance of the styryl feature to the $\mathrm{ONOO}^{-}$scavenging activity, since these two compounds only differ in this aspect, being the first considerably less effective than the second. The results provided by the flavonoids in this study, as well as the structure-activity relationships, are in agreement with other previous works. ${ }^{39-42}$

The results from the assays performed in the presence of $25 \mathrm{mM} \mathrm{NaHCO} 3$ show a decrease in the effect of the catecholic B-ring-like compounds, either 2-styrylchromones or flavonoids. The same behavior was previously observed for quercetin and luteolin by other authors. ${ }^{39}$ On the contrary, apigenin and chrysin were shown to be more effective in the presence of bicarbonate. These variations take place due to the formation of other $\mathrm{ONOO}^{-}$derivatives when bicarbonate is added to the reaction medium at physiological concentrations. The extremely fast reaction between $\mathrm{ONOO}^{-}$and $\mathrm{CO}_{2}$ $\left(K=3-5.8 \times 10^{4} \mathrm{M}^{-1} \mathrm{~s}^{-1}\right)^{43,44}$ originates the nitrosoperoxycarbonate anion $\left(\mathrm{ONOOCO}_{2}^{-}\right)$, whose decomposition leads to the formation of different species including the highly reactive ${ }^{-} \mathrm{NO}_{2}$ and $\mathrm{CO}_{3}{ }^{-}$radicals. ${ }^{45}$ The presence of these radicals in solution affects the reactivity of the $\mathrm{ONOO}^{-}$scavengers, either increasing or decreasing their effects. Nevertheless, the results of the assays in which $\mathrm{NaHCO}_{3}$ was added give us, theoretically, a better approach to the developments in a biological system. In fact it is likely that many of the reactions of $\mathrm{ONOO}^{-}$in vivo are promoted by $\mathrm{ONOOCO}_{2}{ }^{-}$derivatives, which are more efficient nitrating and oxidizing species than $\mathrm{ONOO}^{-}{ }^{45,46}$

The most studied $\mathrm{ONOO}^{-}$-dependent effect in biological targets has been the nitration of tyrosine into 3nitrotyrosine, which is a biomarker for RNS and has been associated with several diseases. ${ }^{18,25}$ Luteolin and quercetin have been classified as excellent inhibitors of tyrosine nitration. ${ }^{47}$ The catecholic B-ring, present in both referred flavonoids, plays an essential role in what concerns the inhibition process. This can be explained by the mechanism behind the reaction of catechol like compounds with peroxynitrite derivatives, which is likely to involve two electron transfer reactions with the formation of $o$-quinones. ${ }^{47-49}$ Considering the structural similarity between the above-referred flavonoids and the 2-styrylchromones from group 1, it is very likely that these compounds can offer a biologically relevant protection against $\mathrm{ONOO}^{-}$-induced deleterious effects.

In agreement with the results from other ROS/RNS, the -NO scavenging activity of 2-styrylchromones depends mostly on the hydroxylation pattern of the B-ring. The compounds with a $3^{\prime}, 4^{\prime}$-catecholic group were shown to be very potent protectors of the NO-dependent oxidation of DAF-2. The other 2-styrylchromones provided a much weaker effect or no effect at all. Strangely, compound $\mathbf{3 A}$ was more effective than $\mathbf{2 A}$, regardless of the additional $\mathrm{C}^{\prime}{ }^{\prime}-\mathrm{OH}$ in the latter. Quercetin and luteolin, in spite of the high effects presented, were less potent scavengers than 2-styrylchromones from group 1. Here, as in other previously exposed cases, the styryl feature seems to improve the scavenging efficiency.

van Acker and coworkers ${ }^{50}$ studied the ${ }^{-\mathrm{NO}}$ scavenging activities of some therapeutically used flavonoids, which were shown to be very effective scavengers. These authors found a correlation between their scavenging potencies and the respective therapeutic efficacy in terms of protection against capillary permeability and fragility and anti-inflammatory and anti-odemic activities. Indeed, 'NO presents pro-inflammatory effects including augmentation of vascular permeability of inflamed tissues, the induction of cyclooxygenase as well as angiogenic and inflammatory cytokines, activation of matrix metalloprotease, induction of chondrocyte apoptosis, and the generation of $\mathrm{ONOO}^{-}$by reaction with $\mathrm{O}_{2} \cdot{ }^{-} \cdot{ }^{19}$ From this point of view, the high ${ }^{-N O}$ scavenging activity shown by some of the compounds tested in our work can possibly be of therapeutic interest.

In conclusion, the scavenging activities for ROS/RNS of 2 -styrylchromone derivatives were investigated for the first time, in the present work, providing motivating results. Some of the studied compounds were shown to be remarkable scavengers of those reactive species. 2-Styrylchromones are, therefore, promising molecules with potential therapeutic value that should be further explored, particularly in what concerns their utility to prevent or control oxidative stress-related diseases whose actual therapeutic options are still unsatisfactory. Clearly, the therapeutic use of the tested 2-styrylchromones still requires a battery of in vitro and in vivo toxicological assays, to confirm their efficacy and assure their safety. Nevertheless, previous results obtained by our group give an excellent indication about their value, since, besides the protective effect against $t$-BHP, the tested 2-styrylchromones were not toxic at concentrations up to $200 \mu \mathrm{M} .^{8}$

\section{Experimental}

\subsection{Equipment}

A microplate reader (Synergy HT, BIO-TEK), with spectrophotometric, fluorimetric, and chemiluminometric detection, plus temperature control capacity, was used for all ROS and RNS scavenging assays.

\subsection{Chemicals}

All the chemicals and reagents were of analytical grade. Dihydrorhodamine 123 (DHR), 4,5-diaminofluorescein (DAF-2), 30\% hydrogen peroxide, ascorbic acid, sodium hypochlorite solution, with $4 \%$ available chlorine, lipoic acid, diethylenetriaminepentaacetic acid (DTPA), 3(aminopropyl)-1-hydroxy-3-isopropyl-2-oxo-1-triazene (NOC-5), $\beta$-nicotinamide adenine dinucleotide (NADH), phenazine methosulfate (PMS), nitroblue tetrazolium chloride (NBT), penicillamine, propyl gallate, rutin, lucigenin, ebselen, luteolin, apigenin, 5-hydroxyflavone, and 
7-hydroxyflavone were obtained from Sigma-Aldrich (St. Louis, USA). $\alpha, \alpha^{\prime}$-Azodiisobutyramidine dihydrochloride (AAPH), histidine, and trolox were obtained from Fluka Chemie GmbH (Steinheim, Germany). Fluorescein sodium salt, quercetin and chrysin were obtained from Aldrich (Milwaukee, USA). All the other reagents were obtained from Merck (Darmstadt, Germany).

2-Styrylchromones 1A-1D, 2A-2D, and 3A-3D were synthesized according to procedures described in the literature by some of the authors. ${ }^{51}$

\subsection{ROS and RNS scavenging assays}

4.3.1. Superoxide radical scavenging assay. Superoxide radical was generated by the NADH/PMS system and the $\mathrm{O}_{2}{ }^{--}$scavenging activity was determined spectrophotometrically in the microplate reader by monitoring the effect of the compound to be tested on the $\mathrm{O}_{2}{ }^{--}$-induced reduction of NBT at $560 \mathrm{~nm}$ for $2 \mathrm{~min}$. The $\mathrm{O}_{2}{ }^{--}$production was controlled by superoxide dismutase (SOD), which inhibited NBT reduction in a concentration-dependent manner. ${ }^{52}$ The assay was performed at room temperature. The reaction mixtures in the sample wells contained the following reactants at the indicated final concentrations (in a final volume of $300 \mu \mathrm{L}$ ): NADH $(166 \mu \mathrm{M})$, NBT $(43 \mu \mathrm{M})$, the tested compounds at various concentrations, dissolved in DMSO, and PMS $(2.7 \mu \mathrm{M})$. NADH, NBT, and PMS were dissolved in $19 \mathrm{mM}$ phosphate buffer, $\mathrm{pH}$ 7.4. No direct effect was observed between DMSO and $\mathrm{O}_{2}{ }^{--}$in the present assay conditions. The antioxidant propyl gallate was used as positive control. The effects were expressed as the inhibition (in percentage) of the NBT reduction to diformazan. Each study corresponds to four experiments, performed in triplicate.

4.3.2. Hydrogen peroxide scavenging assay. The $\mathrm{H}_{2} \mathrm{O}_{2}$ scavenging activity was measured by monitoring the $\mathrm{H}_{2} \mathrm{O}_{2}$-induced oxidation of lucigenin, using a previously described chemiluminescence methodology, ${ }^{53}$ with modifications. Reaction mixtures contained the following reagents at the indicated final concentrations (in a final volume of $250 \mu \mathrm{L}$ ): $50 \mathrm{mM}$ Tris- $\mathrm{HCl}$ buffer, $\mathrm{pH} 7.4$, lucigenin $(0.8 \mathrm{mM})$, dissolved in the buffer solution, the tested compounds at various concentrations, dissolved in DMSO, and $1 \% \mathrm{H}_{2} \mathrm{O}_{2}$. The assays were performed at $37^{\circ} \mathrm{C}$. The chemiluminescence signal was detected in the microplate reader immediately after the plate introduction. The endogenous antioxidant ascorbic acid was used as positive control. The effects were expressed as the inhibition (in percentage) of the $\mathrm{H}_{2} \mathrm{O}_{2}$-induced oxidation of lucigenin. Each study corresponds to four experiments, performed in triplicate.

4.3.3. Hypochlorous acid scavenging assay. $\mathrm{HOCl}$ was measured by using a previously described fluorescent methodology, ${ }^{54}$ based on the $\mathrm{HOCl}$-induced oxidation of DHR to rhodamine 123, which has been adapted to a microplate reader. $\mathrm{HOCl}$ was prepared immediately before use by adjusting the $\mathrm{pH}$ of a $1 \%(\mathrm{~m} / \mathrm{v})$ solution of $\mathrm{NaOCl}$ to 6.2 with dropwise addition of $10 \%$ $\mathrm{H}_{2} \mathrm{SO}_{4}$. The concentration of $\mathrm{HOCl}$ was further deter- mined spectrophotometrically $\mathrm{y}^{55}$ at $235 \mathrm{~nm}$ using the molar absorption coefficient of $100 \mathrm{M}^{-1} \mathrm{~cm}^{-1}$ and the proper dilution was made in a $100 \mathrm{mM}$ phosphate buffer at $\mathrm{pH}$ 7.4. A $2.89 \mathrm{mM}$ stock solution of DHR in dimethylformamide was purged with nitrogen and stored at $-20^{\circ} \mathrm{C}$. Working solutions of DHR were diluted in the phosphate buffer from the stock solution immediately before the determinations and placed on ice, in the dark. Reaction mixtures contained the following reactants at the indicated final concentrations (in a final volume of $300 \mu \mathrm{L}$ ): $100 \mathrm{mM}$ phosphate buffer solution at $\mathrm{pH} \mathrm{7.4,} \mathrm{the} \mathrm{tested} \mathrm{compounds} \mathrm{at} \mathrm{different} \mathrm{concentra-}$ tions, dissolved in ethanol, DHR $(5 \mu \mathrm{M})$, and $\mathrm{HOCl}$ $(5 \mu \mathrm{M})$. The fluorimetric assays were performed at $37^{\circ} \mathrm{C}$, in the microplate reader, at the emission wavelength $528 \pm 20 \mathrm{~nm}$ with excitation at $485 \pm 20 \mathrm{~nm}$. The fluorescence signal was measured immediately after the plate introduction. Lipoic acid was used as positive control. The results were expressed as the inhibition (in percentage) of $\mathrm{HOCl}$-induced oxidation of DHR. Each study corresponds to four experiments, performed in triplicate.

4.3.4. Singlet oxygen scavenging assay. The ${ }^{1} \mathrm{O}_{2}$ scavenging activity was measured by monitoring the oxidation of non-fluorescent DHR to fluorescent rhodamine 123 by this ROS, according to a recently developed fluorimetric methodology. ${ }^{56}{ }^{\mathrm{I}} \mathrm{O}_{2}$ was generated by the thermal decomposition of a previously synthesized water-soluble endoperoxide [disodium 3,3'-(1,4-naphthalene)bispropionate $\left.\left(\mathrm{NDPO}_{2}\right)\right] . \mathrm{NDPO}_{2}$ working solutions, diluted in $100 \mathrm{mM}$ phosphate buffer, $\mathrm{pH}$ 7.4, were prepared immediately before each assay. A $2.89 \mathrm{mM}$ stock solution of DHR in dimethylformamide was purged with nitrogen and stored at $-20^{\circ} \mathrm{C}$. Working solutions of DHR were diluted in the phosphate buffer from the stock solution immediately before the determinations and placed on ice, in the dark. Histidine solutions in phosphate buffer were daily prepared. Reaction mixtures contained the following reactants at the indicated final concentrations (in a final volume of $250 \mu \mathrm{L})$ : Histidine $(10 \mathrm{mM})$, the tested compounds at different concentrations dissolved in DMSO, DHR $(50 \mu \mathrm{M})$, and $\mathrm{NDPO}_{2}(1 \mathrm{mM})$. The fluorimetric assays were performed at $37^{\circ} \mathrm{C}$, in the microplate reader, using the emission wavelength $528 \pm 20 \mathrm{~nm}$ with excitation at $485 \pm 20 \mathrm{~nm}$. The fluorescence was measured after a $30 \mathrm{~min}$ incubation period. Penicillamine was used as positive control. The results were expressed as the inhibition (in percentage) of ${ }^{1} \mathrm{O}_{2^{-}}$ induced oxidation of DHR. Each study corresponds to four experiments, performed in triplicate.

4.3.5. Peroxyl radical scavenging assay. The ROO' scavenging activity was measured by monitoring the fluorescence decay resulting from $\mathrm{ROO}^{\circ}$-induced oxidation of fluorescein and expressed as the 'Oxygen Radical Absorbance Capacity' (ORAC), according to a previously described method. ${ }^{38}$ ROO was generated by thermodecomposition of AAPH. Reaction mixtures in the sample wells contained the following reagents at the indicated final concentrations (in a final volume of $200 \mu \mathrm{L})$ : fluorescein $(61 \mathrm{nM})$, the tested compounds $(0.1-0.8 \mu \mathrm{M})$, dissolved in acetone and subsequently di- 
luted in $75 \mathrm{mM}$ phosphate buffer, $\mathrm{pH} 7.4$, and AAPH $(19 \mathrm{mM})$. Working solutions of fluorescein were diluted in $75 \mathrm{mM}$ phosphate buffer, $\mathrm{pH} 7.4$, to $1 / 5000$-fold, from a $1.53 \mathrm{mg} / \mathrm{mL}$ stock solution, which had been previously prepared and kept at $\approx 4{ }^{\circ} \mathrm{C}$. AAPH was dissolved in phosphate buffer. The mixture was preincubated in the microplate reader for $15 \mathrm{~min}$ at $37^{\circ} \mathrm{C}$. The fluorescence signal was then monitored every minute at the emission wavelength $528 \pm 20 \mathrm{~nm}$ with excitation at $485 \pm 20 \mathrm{~nm}$ until the total decay of fluorescence. Trolox $(1-6 \mu \mathrm{M})$ was used as a control standard in each assay. Each study corresponds to four experiments, performed in triplicate.

ORAC values were calculated according to a previous paper. ${ }^{57}$ The net protection provided by a putative antioxidant sample was calculated using the difference between the area under the fluorescence decay curve in the presence of the sample $\left(\mathrm{AUC}_{\mathrm{sample}}\right)$ and in its $\mathrm{ab}$ sence $\left(\mathrm{AUC}_{\mathrm{blank}}\right)$. Regression equations between net AUC and the concentration of the sample were calculated for all the compounds. ORAC values were calculated by using the standard curve of each assay. Final results were expressed in micromole of Trolox equivalents/ $\mu \mathrm{mol}$ of compound.

4.3.6. Peroxynitrite scavenging assay. The $\mathrm{ONOO}^{-}$scavenging activity was measured by monitoring the $\mathrm{ONOO}^{-}$-induced oxidation of non-fluorescent DHR to fluorescent rhodamine 123, according to a described procedure. ${ }^{58} \mathrm{ONOO}^{-}$was synthesized as described before. ${ }^{58}$ Briefly, an acidic solution $(\mathrm{HCl} 0.7 \mathrm{M})$ of $\mathrm{H}_{2} \mathrm{O}_{2}$ $0.6 \mathrm{M}$ was mixed with $\mathrm{NaNO}_{2} 0.66 \mathrm{M}$ in a $\mathrm{Y}$ junction and the reaction mixture was quenched with ice-cold $\mathrm{NaOH} 3 \mathrm{M}$. Residual $\mathrm{H}_{2} \mathrm{O}_{2}$ was removed by mixing with granular $\mathrm{MnO}_{2}$ pre-washed with $\mathrm{NaOH} 3 \mathrm{M}$. The obtained $\mathrm{ONOO}^{-}$solution was filtered and then frozen $\left(-80^{\circ} \mathrm{C}\right)$. Prior to each experiment, the top layer of the stock solution was collected and the concentration of peroxynitrite was determined spectrophotometrically $\left(\varepsilon_{302 \mathrm{~nm}}=1670 \mathrm{M}^{-1} \mathrm{~cm}^{-1}\right)$. Subsequently, the proper dilution was made in $0.05 \mathrm{M} \mathrm{NaOH}$. A stock solution of $2.89 \mathrm{mM}$ DHR in dimethylformamide was purged with nitrogen and stored at $-20^{\circ} \mathrm{C}$. Working solutions of DHR, properly diluted with the buffer solution $\left(90 \mathrm{mM} \mathrm{NaCl}, 50 \mathrm{mM} \mathrm{Na} \mathrm{PO}_{4}\right.$, and $5 \mathrm{mM} \mathrm{KCl}, \mathrm{pH}$ 7.4), were placed on ice, in the dark, immediately before the determinations. In the beginning of the experiments, $100 \mu \mathrm{M}$ DTPA was added to the buffer. Reaction mixtures contained the following reactants at the indicated final concentrations (in a final volume of $300 \mu \mathrm{L}$ ): DHR $(5 \mu \mathrm{M})$, the tested compounds at different concentrations, dissolved in DMSO, and $\mathrm{ONOO}^{-}(600 \mathrm{nM})$. The assays were performed at $37^{\circ} \mathrm{C}$. The fluorescence signal was detected after a 2 min incubation period at the emission wavelength $528 \pm 20 \mathrm{~nm}$ with excitation at $485 \pm 20 \mathrm{~nm}$, in the microplate reader. Ebselen was used as positive control. In a parallel set of experiments, the assays were performed in the presence of $25 \mathrm{mM}$ $\mathrm{NaHCO}_{3}$ in order to simulate the physiological $\mathrm{CO}_{2}$ concentrations. This evaluation is important because, under physiological conditions, the reaction between $\mathrm{ONOO}^{-}$and bicarbonate is predominant, with a very fast rate constant $\left(K_{2}=3-5.8 \times 10^{4} \mathrm{M}^{-1} \mathrm{~s}^{-1}\right){ }^{59}$ The results were expressed as the inhibition (in percentage) of $\mathrm{ONOO}^{-}$-induced oxidation of DHR. Each study corresponds to four experiments, performed in triplicate.

4.3.7. Nitric oxide scavenging assay. The $\mathrm{NO}$ scavenging activity was measured by monitoring the $\mathrm{NO}$-induced oxidation of non-fluorescent DAF-2 to the fluorescent triazolofluorescein (DAF-2T), according to a described procedure. ${ }^{58}$ NO was generated by NOC-5. A stock solution of $2.76 \mathrm{mM}$ DAF-2 in DMSO was purged with nitrogen and stored at $-20^{\circ} \mathrm{C}$. Working solutions of DAF-2, diluted with a phosphate buffer solution $\left(\mathrm{KH}_{2} \mathrm{PO}_{4} 50 \mathrm{mM}, \mathrm{pH} 7.4\right)$ to $1 / 368$-fold from the stock solution, were placed on ice, in the dark, immediately before the determinations. The reaction mixtures in the sample wells contained the following reagents at the indicated final concentrations (in a final volume of $300 \mu \mathrm{L})$ : DAF-2 $(5 \mu \mathrm{M})$, the tested compounds at various concentrations, dissolved in DMSO, and NOC-5 $(10 \mu \mathrm{M})$. The assays were performed at $37^{\circ} \mathrm{C}$. The fluorescence signal was detected after a $30 \mathrm{~min}$ incubation period at the emission wavelength $528 \pm 20 \mathrm{~nm}$ with excitation at $485 \pm 20 \mathrm{~nm}$, in the microplate reader. Rutin was used as positive control. The results were expressed as the inhibition (in percentage) of ${ }^{*} \mathrm{NO}$-induced oxidation of DAF-2. Each study corresponds to four experiments, performed in triplicate.

\section{Acknowledgments}

The authors acknowledge FCT and FEDER financial support for the project POCI/QUI/59284/2004 and for the Organic Chemistry Research Unity (QNPNANo. 62). Ana Gomes acknowledges FCT and FSE her $\mathrm{PhD}$ Grant (SFRH/BD/23299/2005).

\section{References and notes}

1. Gerwick, W. H. J. Nat. Prod. 1989, 52, 252.

2. Gerwick, W. H.; Lopez, A.; Van Dyune, G. D.; Clardy, J.; Ortiz, W.; Baez, A. Tetrahedron Lett. 1986, 27, 1979.

3. Doria, G.; Romeo, C.; Forgione, A.; Sberze, P.; Tibolla, N.; Corno, M. L.; Cruzzola, G.; Cadelli, G. Eur. J. Med. Chem. 1979, 14, 347.

4. Desideri, N.; Conti, C.; Mastromarino, P.; Mastropaolo, F. Antiviral Chem. Chemother. 2000, 11, 373.

5. Brion, D.; Le Baut, G.; Zammatio, F.; Pierre, A.; Atassi, G.; Belachm, L. Chem. Abstr. 1991, 116, 106092k.

6. Karton, Y.; Jiang, J. L.; Ji, X. D.; Melman, N.; Olah, M. E.; Stiles, G. L.; Jacobson, K. A. J. Med. Chem. 1996, 39, 2293.

7. Fernandes, E.; Carvalho, F.; Silva, A. M. S.; Santos, C. M. M.; Pinto, D. C. G. A.; Cavaleiro, J. A. S.; Bastos, M. L. J. Enzyme Inhib. Med. Chem. 2002, 17, 45.

8. Fernandes, E.; Carvalho, M.; Carvalho, F.; Silva, A. M. S.; Santos, C. M. M.; Pinto, D. C. G. A.; Cavaleiro, J. A. S.; Bastos, M. L. Arch. Toxicol. 2003, 77, 500.

9. Filipe, P.; Silva, A. M.; Morliere, P.; Brito, C. M.; Patterson, L. K.; Hug, G. L.; Silva, J. N.; Cavaleiro, J. A.; Maziere, J. C.; Freitas, J. P.; Santus, R. Biochem. Pharmacol. 2004, 67, 2207. 
10. Quinn, M. T.; Gauss, K. A. J. Leukoc. Biol. 2004, 76, 760.

11. Babior, B. M. Curr. Opin. Immunol. 2004, 16, 42.

12. Cheeseman, K. H.; Slater, T. F. Br. Med. Bull. 1993, 49, 481.

13. Chen, S. X.; Schopfer, P. Eur. J. Biochem. 1999, $260,726$.

14. Jaeschke, H. Exp. Biol. Med. 1995, 209, 104.

15. Xia, Y.; Zweier, J. L. Anal. Biochem. 1997, 245, 93.

16. Davies, M. J. Photochem. Photobiol. Sci. 2004, 3, 17.

17. Nagano, T. Luminescence 1999, 14, 283.

18. Kostka, P. Anal. Chem. 1995, 67, 411R.

19. Miyasaka, N.; Hirata, Y. Life Sci. 1997, 61, 2073.

20. Vapaatalo, H. Med. Biol. 1986, 64, 1.

21. Halliwell, B.; Hoult, J. R.; Blake, D. R. FASEB J. 1988, 2 , 2867.

22. Cotelle, N.; Bernier, J. L.; Catteau, J. P.; Pommery, J.; Wallet, J. C.; Gaydou, E. M. Free Radical Biol. Med. 1996, 20, 35 .

23. Cao, G.; Sofic, E.; Prior, R. L. Free Radical Biol. Med. 1997, 22, 749 .

24. Middleton, E., Jr.; Kandaswami, C.; Theoharides, T. C. Pharmacol. Rev. 2000, 52, 673.

25. Rice-Evans, C. Curr. Med. Chem. 2001, 8, 797.

26. Silva, M. M.; Santos, M. R.; Caroco, G.; Rocha, R.; Justino, G.; Mira, L. Free Radical Res. 2002, 36, 1219.

27. Arora, A.; Nair, M. G.; Strasburg, G. M. Free Radical Biol. Med. 1998, 24, 1355.

28. Robak, J.; Gryglewski, R. J. Biochem. Pharmacol. 1988, $37,837$.

29. Selloum, L.; Reichl, S.; Muller, M.; Sebihi, L.; Arnhold, J. Arch. Biochem. Biophys. 2001, 395, 49.

30. Hanasaki, Y.; Ogawa, S.; Fukui, S. Free Radical Biol. Med. 1994, 16, 845.

31. Bors, W.; Heller, W.; Michel, C.; Saran, M. Methods Enzymol. 1990, 186, 343.

32. Pietta, P. G. J. Nat. Prod. 2000, 63, 1035.

33. Binsack, R.; Boersma, B. J.; Patel, R. P.; Kirk, M.; White, C. R.; Darley-Usmar, V.; Barnes, S.; Zhou, F.; Parks, D. A. Alcohol Clin. Exp. Res. 2001, 25, 434.

34. Tournaire, C.; Croux, S.; Maurette, M.-T.; Beck, I.; Hocquaux, M.; Braun, A. M.; Oliveros, E. J. Photochem. Photobiol. B: Biol. 1993, 19, 205.

35. Ou, B.; Hampsch-Woodill, M.; Prior, R. L. J. Agric. Food Chem. 2001, 49, 4619.

36. Huang, D.; Ou, B.; Hampsch-Woodill, M.; Flanagan, J. A.; Prior, R. L. J. Agric. Food Chem. 2002, 50, 4437.

37. Saija, A.; Scalese, M.; Lanza, M.; Marzullo, D.; Bonina, F.; Castelli, F. Free Radical Biol. Med. 1995, 19, 481.
38. Fernandes, E.; Costa, D.; Toste, S. A.; Lima, J. L. F. C.; Reis, S. Free Radical Biol. Med. 2004, 37, 1895.

39. Santos, M. R.; Mira, L. Free Radical Res. 2004, 38, 1011.

40. Choi, J. S.; Chung, H. Y.; Kang, S. S.; Jung, M. J.; Kim, J. W.; No, J. K.; Jung, H. A. Phytother. Res. 2002, 16, 232.

41. Heijnen, C. G. M.; Haenen, G. R.; van Acker, F. A.; van der Vijgh, W. J.; Bast, A. Toxicol. in Vitro 2001, 15, 3.

42. Heijnen, C. G. M.; Haenen, G.; Vekemans, J.; Bast, A. Environ. Toxicol. Phar. 2001, 10, 199.

43. Radi, R.; Cosgrove, T. P.; Beckman, J. S.; Freeman, B. A. J. Biochem. 1993, 290, 51.

44. Lymar, S. V.; Hurst, J. K. J. Am. Chem. Soc. 1995, 117, 8867.

45. Squadrito, G. L.; Pryor, W. A. Free Radical Biol. Med. 1998, 25, 392.

46. Jourd'heuil, D.; Miranda, K. M.; Kim, S. M.; Espey, M. G.; Vodovotz, Y.; Laroux, S.; Mai, C. T.; Miles, A. M.; Grisham, M. B.; Wink, D. A. Arch. Biochem. Biophys. 1999, 365, 92.

47. Sadeghipour, M.; Terreux, R.; Phipps, J. Toxicol. in Vitro 2005, 19, 155.

48. Pannala, A. S.; Razaq, R.; Halliwell, B.; Singh, S.; RiceEvans, C. A. Free Radical Biol. Med. 1998, 24, 594.

49. Kerry, N.; Rice-Evans, C. FEBS Lett. 1998, 437, 167.

50. van Acker, S. A.; Tromp, M. N.; Haenen, G. R.; van der Vijgh, W. J.; Bast, A. Biochem. Biophys. Res. Commun. 1995, 214, 755.

51. Santos, C. M. M.; Silva, A. M. S.; Cavaleiro, J. A. S. Eur. J. Org. Chem. 2003, 4575.

52. Valentao, P.; Fernandes, E.; Carvalho, F.; Andrade, P. B.; Seabra, R. M.; Bastos, M. L. J. Agric. Food Chem. 2002, 50, 4989.

53. Gomes, A.; Costa, D.; Lima, J. L. F. C.; Fernandes, E. Bioorg. Med. Chem. 2006, 14, 4568.

54. Rezk, B. M.; Haenen, G. R.; van der Vijgh, W. J.; Bast, A. J. Biol. Chem. 2004, 279, 9693.

55. Aruoma, O. I. Gen. Pharmacol. 1997, 28, 269.

56. Costa, D.; Fernandes, E.; Santos, J.; Pinto, D. C. G. A.; Silva, A. M. S.; Lima, J. L. F. C. Anal. Bioanal. Chem. 2007, 387, 2071.

57. Davalos, A.; Gomez-Cordoves, C.; Bartolome, B. J. Agric. Food Chem. 2004, 52, 48.

58. Fernandes, E.; Gomes, A.; Costa, D.; Lima, J. L. F. C. Life Sci. 2005, 77, 1983.

59. Whiteman, M.; Ketsawatsakul, U.; Halliwell, B. Ann. N. Y. Acad. Sci. 2002, 962, 242. 